\title{
O golpe civil militar de 1964: algumas possibilidades sobre seu significado histórico
}

Renato da Silva Della Vechia*

Resumo: O presente artigo tem como objetivo traçar um breve panorama das condições em que se deu o golpe civil militar no Brasil em 1964. Busca também discutir algumas das interpretações sobre o significado histórico do golpe em si e possíveis desdobramentos, caso os atores envolvidos tivessem feito opções distintas daquelas conhecidas pela história.

Palavras-chave: Golpe Militar. Ditadura Militar. Concepções Históricas.

\section{Introdução}

O golpe militar de 64, fruto de um processo que buscava a consolidação da hegemonia norte-americana em nosso continente ${ }^{1}$, foi responsável por uma brutal repressão político-militar em nosso território. Esse processo articulava tanto interesses externos como internos, como veremos posteriormente.

Muito já se pesquisou sobre esse período, embora muitas questões ainda não estejam suficientemente esclarecidas. Da mesma forma, muitas explicações sobre seu significado foram construídas, tanto baseadas nas questões econômicas como nas eminentemente

\footnotetext{
* Sociólogo, doutor em Ciência Política pela UFRGS. Professor de Ciência Política na UCPel e no PPG em Política Social/UCPel; Coordenador de Extensão da UCPel e do Núcleo de Economia Solidária e Incubação de Cooperativas (NESIC). E-mail: rdellavechia@gmail.com
}

Anos 90, Porto Alegre, v. 19, n. 35, p. 87-109, jul. 2012 
políticas sobre o que representou o golpe militar. Dessas explicações, algumas são contraditórias entre si e outras podem conviver sem que umas necessariamente desautorizem as demais. Muitas das diferenças de interpretação estão baseadas em ênfases diferenciadas sobre o peso de certos determinantes do processo político.

Buscaremos, portanto, não apenas localizar historicamente ( certos fatos fundamentais para o entendimento do período, mas, também, comentar algumas das explicações sobre o significado do golpe militar de 64.

Todo o período do governo João Goulart (desde a tentativa de evitar sua posse, devido à renuncia de Jânio Quadros) foi marcado por conflitos e crises políticas. Qualquer observador mais atento poderia constatar o que estava em jogo e quem estava atrás das movimentações políticas visando a derrubar o governo Jango. A própria construção da saída da crise da legalidade de 1961 já se constituiu em um "golpe branco". Na medida em que esta feria a constituição de 46 e que, além disso, a fórmula parlamentarista encontrada não apenas retirava poderes de Chefe de Governo de Jango, mas inclusive poderes de Chefe de Estado, como a possibilidade de dissolução do Congresso (mecanismo presente nos regimes parlamentaristas), mas que Jango não podia acessar. Até mesmo uma CPI foi instalada no Congresso Nacional para avaliar a entrada ilegal de dinheiro norteamericano para financiar os governos ligados à UDN (Ademar de Barros - SP; Carlos Lacerda - RJ e Magalhães Pinto - MG). Essa CPI, que tinha Tancredo Neves como relator, concluiu que, embora o dinheiro tivesse entrado de forma irregular, não caberia ao poder legislativo nem mesmo opinar sobre qual procedimento adotar, porque esta era uma atribuição do judiciário (DREYFUS, 1981).

Um dos pilares da crítica a Jango, além da acusação de que ele estaria tentando introduzir uma "república sindicalista", era a alta inflação no período. A chamada "república sindicalista" fica por conta da pressão dos trabalhadores urbanos e rurais que reivindicavam mais espaço no bloco de poder, além de todo o imaginário social anticomunista fortalecido durante o período denominado de "guerra fria" entre os chamados bloco socialista (leia-se ex-União Soviética e países satélites) e bloco ocidental (leia-se EUA). 
Quanto aos altos índices de inflação, se comparados aos patamares que tivemos no final dos anos $80 \mathrm{em}$ nosso país, parece ser, em um primeiro momento, um elemento superestimado pelas forças de oposição a Jango, a criação artificial de uma crise política e econômica que não seria tão séria como a imprensa da época buscava demonstrar.

A inflação nesse período inicia ainda no governo Juscelino, eis que nessa época esteve em torno de $30 \%$ ao ano. No governo Jango, ela aumenta, passando dos $60 \%$, em 1963, e, finalmente, atingindo o índice de $80 \%$ ao ano. Se lembrarmos o governo Sarney, veremos que essa era a taxa média mensal da inflação em nosso país.

No entanto, Paul Singer, um economista insuspeito, em função de suas posições políticas de apoio a Jango no período, apresenta uma explicação diferente da simples "armação política" contra o ex-presidente.

Quando estávamos naquela inflação "terrível” de 30\% ao ano da época de Juscelino, recebemos na USP a visita de um economista americano que veio conhecer de perto como era possível sobreviver com uma inflação daquelas, coisa inimaginável de longe. Foi uma dificuldade convencê-lo de que a vida podia ser normal mesmo com os preços em elevação. Mas quando a inflação alcançou 60\% e mais, em 1963-64, a opinião pública se apavorou (SINGER, 1997, p. 15).

A crise econômica do período foi importante fator de mobilização da classe média por parte dos setores mais conservadores da sociedade brasileira. Nesse caso, a Igreja Católica teve um papel fundamental ao organizar as Marchas da Família com Deus pela Liberdade, as quais apresentavam um conteúdo anticomunista e que mobilizaram centenas de milhares de pessoas nas principais capitais do país.

A explicação sobre o significado da grande preocupação social da classe média com a inflação no período decorria da falta de mecanismos de indexação da economia.

Existem diferentes visões de inflação e é importante saber que, quando a inflação não é alta, ela pode ser mais contundente 
nos seus efeitos, porque em geral não é indexada. Nós chegamos a uma indexação perfeita. Depois do golpe de 64, a economia brasileira se tornou uma das economias mais bem indexadas do mundo, com a caderneta de poupança, com os títulos reajustáveis, com a correção monetária de salários, aluguéis, etc. No pré-64 não havia isso. Os pobres, por exemplo, não tinham como fazer poupança. Apesar de uma inflação de 40, 50 ou $60 \%$ não ser uma coisa muito grave, com uma taxa máxima de juros de $12 \%$ ao ano, acaba-se perdendo dinheiro. Então as pessoas pobres procuravam comprar terrenos na periferia porque era a única maneira de formar algum pecúlio. A poupança financeira era quase inexistente (SINGER, 1997, p. 16).

Mesmo não sendo o foco deste trabalho, é necessário fazermos a diferenciação de perspectivas que a inflação tinha durante os governos de Juscelino e de Jango. Enquanto a inflação no período Jango era fruto da crise político-institucional e do grande confronto ideológico da época, a inflação no governo Juscelino possuía uma outra perspectiva. Maria Victória Benevides, na sua obra já clássica sobre o governo de Juscelino, reconhece que a inflação foi a principal arma da oposição ao governo na época. No entanto, entendia que a inflação, longe de ser um problema de descontrole, fazia parte de seu projeto econômico. Baseada em estudo de Otávio Ianni, nos diz

[...] o recurso à inflação garantiu, em parte, o crescimento econômico do país. Em 1956 a taxa de inflação era de 19,2\%, ao passo que em 1960 era de 30,9\%. Nos anos seguintes ela se acentuou, mas no período 56/60 não atingiu níveis inconvenientes com o desenvolvimento. Se, por um lado, provocava distorções na estrutura de investimentos (por exemplo, teria provocado especulação imobiliária), por outro lado funcionava como inflação de lucros, como técnica de poupança forçada, ou melhor, técnica de confisco salarial [...] Assim, a inflação, na perspectiva deste estudo, foi a alternativa mais viável para financiar o Programa de Metas e a construção de Brasilia, uma vez que a reforma tributária (o que significaria meios coercitivos para levantar por vias 
fiscais amplos recursos de investimentos) seria politicamente impossível. (BENEVIDES, 1976, p. 235-236)

No entanto, apesar de todos os indícios de que haveria um acirramento da disputa política, os principais partidos que poderiam organizar algum tipo de reação ao golpe não o fizeram (P'TB e PCB). Dentro do PTB, a posição vacilante de Jango foi determinante no sentido de impedir qualquer tipo de reação por parte da sociedade. Embora poucas figuras, como Brizola, defendessem uma posição mais forte, no sentido da defesa da legalidade, Jango, até mesmo porque acreditava que se houvesse intervenção militar, seria, por um curto espaço de tempo, não aceitou liderar nenhum tipo de reação à ação golpista.

Já a direção do PCB (e diga-se, em dissonância com a posição de boa parte da base do partido), confiava nos "brios democráticos" de nossa oficialidade. Luis Carlos Prestes, secretário-geral do partido, afirmou poucos dias antes do golpe que "Não somos governo, mas estamos no governo".

Um artigo de Mário Alves, publicado na revista Estudos Sociais, de dezembro de 1962, expressa duas análises que a história irá demonstrar serem equivocadas, mas que, no momento, representavam um pouco a linha do seu partido. A primeira é acreditar que a extrema direita tinha sido derrotada e não tinha mais viabilidade histórica. Referia-se a Carlos Lacerda e seus apoiadores:

[...] extremada ala direita dirigida por homens como Carlos Lacerda, ala que se opõe a qualquer compromisso e atua como brigada de choque da reação. Em seu conjunto, estas forças representam o que há de mais obsoleto na estrutura econômico-social e se encontra em franco declínio, do ponto-de-vista histórico (ALVES, 1962, p. 232).

Mais adiante, no mesmo texto, avalia que o imperialismo, com medo de forçar a burguesia nacional a tomar medidas mais drásticas, em função da pressão popular, iria assumir uma posição mais flexível com as mudanças em curso. 
[...] Entre os fatores que condicionam a conduta política da burguesia nacional, não se deve omitir a própria ação do imperialismo norte-americano, compreendendo o papel ascendente deste setor capitalista no Estado brasileiro, as tendências da nova situação mundial, assim como a elevação da consciência nacional na América Latina após a revolução cubana, os círculos monopolistas dos Estados Unidos procuram formular uma tática mais flexível nas relações com as classes dominantes de nosso país. Esforçam-se por ampliar a base social de sua dominação, através de um compromisso com os setores políticos que representam a burguesia nacional, considerando que a velha oligarquia vinculada ao latifúndio e subserviente ao capital estrangeiro perde rapidamente a influência sobre o povo e já não constitui um suporte firme para a sustentação de seus interesses (Ibidem).

Os dois elementos centrais desta análise (que o golpe se encarregaria de mostrar como equivocados) são: a ideia de que a extremada ala direita está sem perspectivas históricas e a de que o imperialismo poderia fazer concessões para viabilizar um governo de centro-esquerda.

Quando o golpe militar eclodiu na noite do dia 31 de março de 1964, o conjunto dos movimentos sociais, notadamente os movimentos sindical, estudantil e de luta pela terra, através das Ligas Camponesas, é pego de surpresa. Não que não soubessem que a possibilidade do golpe vir era grande, mas surpresa no sentido de não saber o que fazer. Durante a madrugada, muitos sindicatos fazem vigília tentando organizar algum tipo de reação. A sede da União Nacional de Estudantes é incendiada. Jango pega um avião e se dirige a Porto Alegre, onde Brizola já o esperava no aeroporto, e logo se dirige ao Uruguai, país em que Brizola mais tarde também irá se refugiar. Naquela noite, centenas de pessoas são presas nos quartéis de nosso país. A desorganização e confusão, no entanto, não ocorre só do lado dos apoiadores de Jango.

[...] conspiradores. Salvou-os a capitulação precipitada de João

Goulart. É uma idéia falsa a de que os golpistas estivessem 
fortemente articulados. Pelo contrário, a articulação era frouxa e havia muita desconexão. Mourão Filho tomou a iniciativa de movimentar as tropas de Minas Gerais por conta própria, Castello Branco ficou assustado, mandou até o recado para que se detivesse, não avançando de Juiz de Fora e de Belo Horizonte para o Rio de Janeiro. No Rio de Janeiro a detonação do golpe provocou confusão entre os (GORENDER, 1998, p. 112).

Gorender também acha falsa a ideia de que o golpe era inevitável, bem como de que não havia condições de reação a ele.

Os próprios golpistas do Rio ficaram surpresos com a iniciativa do General Olímpio Mourão, em Minas. Naquele momento, se houvesse um comando realmente combativo das forças que queriam as reformas de base, a ação de esquadrilhas de bombardeiros e de aviões de caça teria paralisado a coluna do general Mourão, que descia de Minas, dispersando aquela tropa, o que teria um efeito moral tremendo. [...] No dia 31, também, se o fuzileiros navais tivessem recebido ordens do almirante Aragão (que aguardava um sinal de Jango) e desencadeassem uma ação da tomada do Palácio Guanabara, no Rio de Janeiro, onde a defesa era muito precária, teria sido possível prender Lacerda, o que também provocaria um efeito moral de enorme importância em todo o Brasil. Mas isso não ocorreu (Ibidem, p. 114).

Curiosamente, em um primeiro momento, o governo Castelo Branco agiu com rigor, mas com certos limites. Dentro de um contexto de golpe militar, em diversos locais, as pessoas detidas eram apenas orientadas a não se contrapor ao novo regime. $\mathrm{Na}$ medida em que até aquele momento as pessoas haviam atuado dentro da constituição, defendendo a legitimidade de um governo constituído, elas não seriam importunadas. No entanto, eram também advertidas de que havia sido modificada a nova ordem constitucional e, desse momento em diante, não seria admitida oposição ao novo regime.

Não havia, inicialmente, uma intenção de uma continuidade do regime militar no tempo. Nem de parte dos civis quanto de 
importantes setores militares. Tanto é que, em outubro, a UDN definiu-se pela candidatura de Carlos Lacerda à Presidência da República nas eleições previstas para 1965. Também Juscelino faz suas movimentações para sair candidato. Até mesmo o primeiro Ato Institucional do regime militar não é numerado. Com a continuidade dos Atos Institucionais no tempo é que serão numerados (AI-2, AI-3 etc).

Mas, com o passar do tempo, as lutas internas dentro das forças armadas começaram a criar um outro quadro, no qual a repressão tendia a se acentuar cada vez mais. Neste momento, notadamente o movimento estudantil começa a se recuperar do "estado de choque" e volta às ruas exigindo mais vagas nas universidades (luta dos estudantes secundaristas) e combatendo as tentativas de modificação do sistema educacional, através dos acordos MEC-USAID, além, é claro, das reivindicações democráticas mais gerais.

O chamado "golpe dentro do golpe", que resultou no fechamento do Congresso e na instauração do AI-5 (1968), resultou em um exacerbamento da violência policial em proporções nunca vistas em nosso país, fruto da vitória da chamada "linha dura" dentro das fileiras das Forças Armadas.

Segundo dados de estudo feito pela Arquidiocese de São Paulo, intitulado de Brasil: Nunca Mais, durante os primeiros atos do governo Castelo Branco, 378 políticos tiveram seus mandatos cassados; 122 oficiais foram reformados. Ao final do governo Geisel, mais de 10 mil funcionários públicos foram demitidos; mais de 10 mil exilados; 245 estudantes foram expulsos das universidades, sem direito de estudar durante o período de 10 anos; mais de 3 centenas de pessoas foram mortas ou desaparecidas; 4.682 pessoas foram cassadas, mais de 5 mil inquéritos policiais, envolvendo mais de 40 mil pessoas; milhares de presos e torturados. Das prisões ocorridas, $84 \%$ delas não foram comunicadas aos juízes (6.256); 12\% foram comunicadas fora do prazo legal (816 casos) e apenas 4\% (295 casos) foram prisões comunicadas aos juízes nos prazos legais.

A maioria das análises deste período coloca os militares como os grandes vilões do período. O desgaste que as Forças Armadas tiveram frente à população, em função deste momento, ainda está presente e ficará marcado na memória de nosso povo por muito tempo. No 
entanto, é importante percebermos dois fatores: o primeiro é que não podemos julgar os militares e as Forças Armadas como um todo homogêneo. Afinal, segundo os dados do relatório Brasil: Nunca Mais, 122 oficiais foram sumariamente reformados pelo primeiro Ato Institucional, somente nos primeiros dois meses posteriores ao golpe. Com o AI-5, mais 241 militares foram reformados; 284 marinheiros e fuzileiros foram processados por participar das mobilizações políticas de março de 64, mobilizações anteriores ao golpe. Muitos outros foram perseguidos e até mesmo mortos e torturados.

Houve uma hegemonia conservadora dentro do governo militar que colocou o estado brasileiro a serviço de interesses de grandes grupos econômicos. ${ }^{2} \mathrm{O}$ segundo fator, que precisa ser considerado, é que a repressão teve não só a participação decisiva, como o apoio econômico de grandes grupos empresariais privados. A Operação Bandeirantes (a famigerada OBAN) ${ }^{3}$ constituiu-se como um grupo paramilitar de apoio ao regime e de extermínio dos envolvidos na contestação à ditadura militar. Financiada com capital privado, viabilizou as chamadas "casas da morte", pequenos sítios que serviam como locais apropriados para interrogatórios, torturas e ocultação de cadáveres, na medida em que esses locais ficavam distantes de cidades e/ou vizinhos. Os grandes beneficiários do golpe não foram apenas os militares. Estes foram determinantes e todos os envolvidos nas ilegalidades do regime ainda têm esta dívida a ser paga perante o povo brasileiro, na medida em que a anistia encaminhada, ao final do ciclo militar, também foi um instrumento para garantir a impunidade dos responsáveis por muitos dos crimes cometidos. No entanto, muitas vezes esquecemos de mencionar os grupos econômicos e os setores políticos que deram sustentação e patrocinaram as atrocidades cometidas. Mesmo que não tenham participado diretamente do "serviço sujo", em nome da memória de todos os mortos e "desaparecidos" pelo regime, não devemos esquecer a participação e conivência de muitos dos políticos e empresários que atualmente assumem posturas "democráticas" e "progressistas", além de parcelas do empresariado e intelectuais que assumiram postos na estrutura do estado, constituindo-se em parte importante da tecnoburocracia estatal. ${ }^{4}$

A falta de espaços políticos para a atuação legal em que a oposição aos projetos do regime militar pudessem se expressar vai 
impulsionar um forte movimento de contestação ao regime, notadamente através do movimento estudantil. A situação social dos estudantes lhes permitia atuar de forma mais articulada que outros setores da sociedade. Aquilo que Bourdieu e Passeron (1968) irão definir como uma relação própria que a juventude estabelece com o tempo e o espaço permitirá que os jovens liderem movimentos de protestos que os sindicalistas não podiam encaminhar, em função de uma maior repressão; de estarem com os seus sindicatos controlados por interventores nomeados pelo governo e pela necessidade de preservar seus empregos para sustentar suas famílias.

No entanto, a prisão de mais de 700 lideranças estudantis, ainda em 67, no Congresso de Ibiúna, vai expô-las muito. Ao mesmo tempo, o acirramento da luta da juventude, não só no Brasil, mas em diversas partes do mundo, vai colocar o regime na defensiva, em um primeiro momento, e logo ele irá desencadear o recrudescimento da repressão. As lutas travadas, principalmente em São Paulo e Rio de Janeiro, foram determinantes para a criação do AI-5.

No Rio, a luta contra o fechamento do Calabouço (casa de estudante e restaurante universitário) foi um momento importante de acumulação política por parte dos estudantes. $\mathrm{O}$ assassinato do estudante Ëdson Luis ${ }^{5}$, no Calabouço, irá gerar uma grande repercussão social, não só no Rio como também em outros estados. No Rio é organizada a passeata dos 100 mil. Costa e Silva, temeroso das consequências, resolve negociar. É escolhida uma comissão de estudantes e intelectuais. Faziam parte da comissão: o psicanalista Hélio Pellegrino, o professor José Américo Pessanha, o assessor jurídico do grupo, o advogado Marcelo Alencar, o padre João Batista Ferreira e os estudantes Franklin Martins e Marcos Medeiros. Marcos Medeiros era militante do PCBR (posteriormente irá concorrer à presidência da UNE) e Franklin Martins também foi militante, sendo que ficou pouco tempo e após foi militante no MR-8.

Zuenir Ventura, em seu livro intitulado 1968: o Ano que não terminou, dá um relato sobre o desfecho da reunião entre a chamada "Comissão dos 100 mil" e Costa e Silva. Após uma reunião muito tensa, na qual os estudantes queriam a liberdade de seus colegas presos (9 estudantes), a partir de certo momento, Marcos Medeiros perdeu a paciência e perguntou: 
- Escuta aqui, professor, eu quero saber o seguinte: o senhor vai ou não vai soltar os nossos companheiros?

Nunca se soube se o presidente ficou mais irritado com o tratamento indevido ou se com o tom de ultimato. O que se sabe é que o barulho da cadeira presidencial rodando, quase caindo, precedeu o ruído de duas mãos espalmadas desabando sobre a mesa. Era o marechal e não o presidente, quem, de pé, reagia:

Eu não aceito ultimato, nem desrespeito. A dignidade da Presidência não admite ameaças. Está encerrada a reunião (VENTURA, 1988, p. 179).

O fim desse diálogo encerra toda e qualquer possibilidade de negociação política do regime com os estudantes. A partir deste momento, o único caminho que se constitui é o do confronto direto.

$\mathrm{Na}$ medida em que o PCB, principal partido de esquerda no país, opunha-se à ideia de luta armada e sustentava a ideia de transição pacífica ao socialismo e à busca de alianças políticas internas para combater o regime a partir de um acúmulo a ser construído nos movimentos sociais, o rompimento dentro do partido era inevitável. Com a cisão no PCB, irão surgir diversas organizações que, sob diferentes análises sobre as estratégias e condições de luta, irão adotar formas diferenciadas de luta armada, seja na intensidade, seja no tipo de ação a desencadear ou até mesmo no que se refere ao terreno ideal de luta (campo ou cidade). Fruto da falta de táticas e estratégias comuns, e de uma cultura sectária e/ou vanguardista, surge uma enorme pulverização dessa esquerda que busca o caminho armado (ALN; MR-8; PCBR; PCR; POC; VPR; VAL-Palmares etc.).

Com a impossibilidade da retomada do movimento de massas, começa a articular-se no país a preparação para a luta armada. O AI-5 reforça essa posição, na medida em que é entendido como uma manifestação de fraqueza do regime. Ou seja, já que não tinha capacidade de controlar a situação através da hegemonia, instaurase a força como espaço de dominação. Essa análise irá se mostrar equivocada em função do início de um crescimento econômico que já se apresentava no início dos anos 70 . No entanto, a dinâmica de clandestinidade e o exemplo de outras lutas que foram e/ou estavam 
sendo travadas em outras partes do mundo (revolução cubana; guerra do Vietnã; maio de 68 etc.) não permitiram que os agrupamentos de esquerda, que tinham optado pela via armada como forma de derrubar o regime, enxergassem essa realidade.

Talvez o primeiro a alertar para este fato tenha sido Jacob Gorender, dirigente do PCBR, que, juntamente com Apolônio de (Carvalho, defendia uma posição de recuo na questão militar. Entendia que a classe média tenderia a ser cooptada em função do crescimento econômico do país e que isso isolaria qualquer tentativa de luta armada. No entanto, entre os que romperam com o PCB, nem mesmo em seu partido (Partido Comunista Brasileiro Revolucionário), Gorender conseguiu ser ouvido. Mário Alves e parte da direção do PCBR tinham outra posição, achando que não era momento de recuar. A reunião do Comitê Central, convocada para janeiro de 1970, em que iria ser discutida essa questão, não chegou a se realizar, em função de um conjunto de prisões e mortes de seus dirigentes. Entre eles o assassinato de Mário Alves, o que levará o PCBR, assim como os demais grupos da época, à intensificação das ações militares.

Mais adiante, em 1973, Fernando Henrique Cardoso, que, embora tivesse sido demitido do cargo de professor da USP, não estava em situação de clandestinidade, irá reforçar a ideia do crescimento econômico como o grande obstáculo a qualquer tipo de luta política mais frontal com o regime.

Outro equívoco, muito comum nas análises sobre o regime militar, é a sua classificação como um regime fascista. Se é verdade que muitas vezes os métodos de perseguição política não se diferenciavam de regimes fascistas, existe uma profunda diferenciação em relação a eles. Adotar indiscriminadamente denominações deste tipo (fascismo, populismo etc.), sem precisar seu conteúdo, pode levar a generalizações que não conseguem definir com precisão os conceitos utilizados.

Juan Linz constrói uma definição de regimes autoritários, os quais se diferenciam tanto dos regimes democráticos (por obviedade), como também dos regimes totalitários (distinção nem sempre feita). Os regimes fascistas, para ele, estão dentro da definição de totalitários, e os autoritários seriam definidos como 
[...] Sistemas políticos com pluralismo limitado, não responsável, sem ideologia orientadora e elaborada, mas com mentalidades distintas, sem mobilização política extensiva ou intensiva, exceto em alguns pontos do seu desenvolvimento, e no qual um lider ou, ocasionalmente, um pequeno grupo exerce o poder dentro de limites formalmente mal definidos, mas na realidade, bem previsíveis (LINZ, 1979, p. 121).

Essa definição é importante para percebermos a diferença de regimes tipo o militar brasileiro com o fascismo. Enquanto os fascismos buscam uma mobilização ativa do povo, a partir de uma ideologia bem definida, buscam a totalidade do social, o nosso caso caracterizou-se, ao contrário, pela busca de um baixo nível de mobilização política. Existia claramente um incentivo à vida privada, que deixava à burocracia do Estado a responsabilidade pela política. Toda ideologia era vista como um mal, como algo exótico, estranho aos interesses do país. Além disso, manteve-se (mesmo que limitado) um certo pluralismo político. Manteve-se um sistema partidário (embora bipartidário) e processos eleitorais, além de institutos como habeas corpus (embora nem sempre respeitado).

Essas duas análises, a de que era um regime fascista, e a de que o uso da força era fruto de uma baixa hegemonia política e ideológica na sociedade, foram muito difundidas, principalmente no "período quente" do regime, em que a própria convulsão política e a falta de informações impedia que análises mais elaboradas fossem feitas.

Posteriomente, outros estudos surgirão tentando compreender o significado histórico deste período. Dentre eles, faremos um breve comentário sobre os principais entendimentos sobre o período militar instituído no Brasil.

Angelina Cheibub Figueiredo (1993) talvez tenha sido quem primeiro se preocupou em sistematizar as diversas definições sobre este período. Classifica em dois conjuntos básicos de explicações: as estruturais e as intencionais.

Quanto às explicações estruturais, também as subdivide entre as que enfatizam os fatores econômicos e as que percebem os fatores políticos e institucionais como centrais. Nos dois casos, entende que são explicações que ao fim levam a uma visão de inevitabilidade do 
surgimento de um regime autoritário, sem margem de escolhas que possam ser relevantes no resultado final.

Na primeira corrente, situa Guilherme O’Donnel e Fernando Henrique Cardoso. O’Donnel busca estabelecer conexões entre estágios de industrialização e regimes autoritários. Não chega a assumir uma posição determinista, mas fala em uma "afinidade eletiva" entre industrialização e autoritarismo. Para ele, na medida em que se aprofunda o processo de substituição de importações e o processo de industrialização acentua-se, surge a necessidade de formas autoritárias para regular os conflitos e para viabilizar o crescimento econômico.

Já Fernando Henrique Cardoso, segundo Argelina, possuía uma visão bem mais determinista.

Afirma que o processo de acumulação exige o desmantelamento dos instrumentos de pressão e defesa disponíveis às classes populares. O autoritarismo decorrente foi, portanto, inevitável por que se tornava necessário reestruturar os mecanismos de acumulação em um nível mais elevado, que se ajustasse melhor aos avanços já obtidos no desenvolvimento das forças produtivas (FIGUEIREDO, 1993, p. 23).

No entanto, no rodapé de seu texto, na página 24, Argelina lembra que o próprio Fernando Henrique Cardoso, posteriormente, irá modificar sua visão sobre esta ideia de inevitabilidade da ditadura militar como forma de preparar as condições para o desenvolvimento do capitalismo atual.

Outro autor que irá analisar e criticar o determinismo de algumas visões econômicas é José Serra. Irá fazer uma crítica a três tipos de teses consideradas por ele como equivocadas.

Examinarei, de um ponto de vista crítico, três hipóteses que versam sobre as relações entre desenvolvimento econômico e regime burocrático-militar. A primeira delas na tentativa de explicar a existência do regime, enfatiza a necessidade inarredável da superexploração dos trabalhadores. A segunda estabelece uma 'afinidade eletiva' entre, por um lado, o autoritarismo e, por outro, a percepção, necessidade 
objetiva e realização de um programa de aprofundamento (profundización) do capitalismo nas economias mais diversificadas da América Latina. A terceira apresenta o 'moderno' autoritarismo como uma espécie de encarnação da racionalidade econômica, necessária para o desenvolvimento do capitalismo na região (SERRA, p. 103).

No primeiro dos três casos citados por Serra, ele se refere à Teoria da Superexploração, de Rui Mauro Marini, embora também refira-se a Gundher Frank. No segundo caso, o "aprofundamento da industrialização” é creditado a Guilherm O’Donnell, e Serra afirma que esta elaboração parte das elaborações da CEPAL (Comissão Econômica para América Latina) no começo dos anos 60 que analisa a substituição de importações. No terceiro caso, em que ele percebe uma relação de causalidade entre regime burocrático-militar e crescimento econômico, Serra lembra que este tipo de argumento foi utilizado não somente pelos ideólogos do regime (Simonsen, Campos), como também por aqueles que, não contentes com o regime, reconheceram virtudes nele, notadamente alguns brasilianistas (Horowitz, Trimberger, Roett e, inclusive, Thomas Skidmore).

Como o objetivo, neste momento, não é realizar uma reflexão sobre os resultados econômicos de 64, mas apenas identificar algumas das concepções que buscaram explicar este período, não iremos nos preocupar em situar as diferentes críticas a estas concepções. Basta neste momento a concepção mais geral, que aponta os limites daquelas concepções que ficaram restritas apenas às questões estruturais econômicas e que, de uma forma maior ou menor, reproduziram algum tipo de "inevitabilidade" do golpe a partir do fenômeno econômico.

No que se refere a um tipo de explicação estrutural, mas que tem no fator político seu elemento central e determinante para as condições do golpe, Argelina Figueiredo cita como exemplo a interpretação de Wanderley Guilherme dos Santos, em que, segundo ele, a paralisia de decisões, decorrente de quatro fatores diferenciados, é o elemento central da explicação do golpe. Esta paralisia seria fruto, basicamente, da inconstância das coalizões que se formaram no Congresso (não percamos de vista a adoção do sistema parlamentarista); a instabilidade 
governamental, fruto, entre outros fatores, de uma grande rotatividade nos principais cargos governamentais; a radicalização ideológica (radicalização que não se dava apenas no terreno nacional) e, enfim, a fragmentação de recursos de poder. Dentre essas variáveis, Santos destaca a radicalização ideológica e a consequente suspeita (de ambas as partes) por parte dos atores envolvidos, como o principal fator que levou a uma diminuição da capacidade de negociação e ao aumento da intransigência no campo político.

Santos mantém a noção de inevitabilidade. De acordo com ele, o impasse que resultou no golpe de 64 'foi a consequência imperiosa de um conflito político caracterizado pela dispersão de recursos entre atores radicalizados, impedindo que o sistema tivesse um desempenho adequado e impelindo-o para o tipo de crise que classificarei de - paralisia decisória (FIGUEIREDO, 1993, p. 26).

Um outro modelo de explicação a que Argelina também se refere é o que ela denominou de explicações intencionais ou "orientadas para o ator". Utiliza-se de dois exemplos de análises que, a seu ver, são insuficientes. Refere-se aos estudos de René Armand Dreifuss e Alfred Stepan.

René Dreifuss (1993, ApudFIGUEIREDO) possui um estudo bastante apurado que tenta comprovar as ligações econômicas que deram sustentação a uma conspiração internacional de direita contra Goulart. Constrói a ideia de uma "elite orgânica" que se articulava principalmente em torno do IPES (Instituto de Pesquisas e Estudos Sociais) e IBAD (Instituto Brasileiro de Ação Democrática). Seus dois principais livros, que sustentam esta tese são: 1964: A Conquista do Estado (mais de 800 páginas) e A Internacional Capitalista: Estratégias e Táticas do Empresariado Transnacional - 1918-1986. Embora em nenhum momento Argelina negue a participação do capital externo na sustentação do golpe de Goulart, avalia que essa é uma interpretação limitada, na medida em que a existência de uma conspiração em si não é suficiente para o seu sucesso. Seria necessário um conjunto de outras condições para que toda e qualquer tentativa de conspiração possa ter viabilidade histórica. 
Quanto a Stepan (ibidem), seus estudos levam à conclusão de que, de certa forma, o que leva ao golpe é a própria qualidade da liderança de Goulart. Em outras palavras, as ações de Jango, principalmente seus últimos atos, o levam a um isolamento crescente. Argelina critica essa perspectiva na medida em que Stepan analisa basicamente o final do governo Goulart e não o conjunto de suas ações. Além disso, ao centrar sua análise na figura de Jango, não leva em conta - ou não dá a devida dimensão - ao importante papel que os demais atores desempenharam.

Argelina Figueiredo, partindo do princípio de que o resultado final do papel dos atores não pode ser reduzido à sua psicologia individual, propõe um estudo na sua conduta estratégica a partir de estruturas históricas concretas. Propõe um modelo de análise baseado em Przeworski (apud, 1986, p. 47), que

[...] concentra-se na conduta estratégica de atores políticos em situações concretas, enfatizando interesses e percepções e formulando os problemas em termos de possibilidades e escolhas.

Assim, as escolhas deliberadas e intencionais feitas pelos atores são o ponto de partida para a análise. A interação entre as escolhas e as ações constitui o mecanismo capaz de explicar a ocorrência de um resultado, dentre os diversos possíveis. Os constrangimentos estruturais constituem o primeiro dispositivo de filtragem 'que estreitam o repertório de cursos de ação abstratamente possíveis e reduz a um subconjunto infinitamente menor de ações exeqüíveis (FIGUEIREDO, 1993, p. 29-30).

A autora busca diferenciar-se de Stepan na medida em que leva em consideração o que denomina de "constrangimentos estruturais" como limitadores das escolhas por parte dos agentes envolvidos. Da mesma forma, analisa as opções assumidas não só por Jango, mas pelo conjunto dos atores envolvidos. No entanto, muito parecido com a análise de Stepan, considera como relevantes as escolhas feitas pelos agentes envolvidos para o resultado final do jogo político. Trabalha 
com a ideia de que estratégias diferentes levarão a resultados diferentes. Sua análise baseia-se na ideia de que as escolhas feitas em diferentes momentos de 61 a 64 foram determinantes no sentido de diminuir as possibilidades de avanço nas reformas políticas e no sentido de diminuição da base política de sustentação de Jango. Parte do princípio de que houve dois grandes momentos em que as reformas poderiam ter ocorrido. Em um primeiro momento, durante o período parlamentarista, e em um segundo momento, já no presidencialismo, com o Plano Trienal e com um projeto de emenda constitucional, apresentado pelo governo que permitiria a desapropriação de terras para a Reforma Agrária. No entanto, essas duas tentativas falharam, o que

[...] estreitou o campo de ações possíveis ao governo e condenou ao fracasso uma tentativa subsequente de se formar uma frente de centro-esquerda que visasse obter um acordo sobre um programa mínimo de reformas e deter o iminente movimento direitista. Nesse momento, a oposição ao governo havia crescido e ampliado sua base de apoio, à medida que outros grupos foram se juntando ao bloco antigovernamental. $\mathrm{O}$ confronto entre os grupos políticos competidores acirrou o crescente consenso negativo em relação às possibilidades de resolver o conflito dentro das regras democrática. (Ibidem, p. 30-31).

Francisco de Oliveira entende que o golpe de 64 foi um rearranjo de classes e setores de classes que disputavam o governo. No entanto, embora reconhecendo a importância do fenômeno econômico, não se reduz a ele. Tampouco trabalha com o que ele denomina de "cesta repleta de alternativas".

Embora a economia tenha um alto grau de sobredeterminação, pois se trata de estruturas capitalistas de acumulação de capital, elas não são imunes à vontade e à capacidade dos homens e dos atores sociais; isso seria uma falsificação do que é forte na economia política.

Apesar disso, é preciso enfatizar que, no pós-64, cada ator, cada classe social, cada representação, cada organização 
política tomou posições e fez opções, inclusive depois da democratização (OLIVEIRA, 1997, p. 28).

\section{Considerações finais}

De forma genérica, talvez exista um consenso mínimo de que o período militar foi fruto de uma articulação a partir da aliança de interesses de setores da burguesia nacional (UDN) com o capital externo. Buscava um desenvolvimento a partir do que podemos denominar de "desenvolvimento dependente", ou seja, a busca de uma articulação com o capital norte-americano, que se propunha a repassar tecnologia e emprestar capital para nosso país. Essa aliança contou com a participação efetiva de parte considerável da alta oficialidade de nossas forças armadas, bem como parcelas do empresariado e da intelectualidade. Afora estes elementos consensuais, as demais análises preocupam-se em precisar os elementos constitutivos desse processo. Particularmente, entendemos que muitas das abordagens vistas anteriormente não são contraditórias e este texto, por sua vez, não procura dar respostas definitivas, mas apenas apresentar um quadro de diferentes explicações sobre o período.

De fato, as diferentes abordagens e análises sobre o golpe de 64 são importantes no sentido de precisar melhor os fatores que levaram ao fracasso da democracia no Brasil e ao surgimento de um estado ditatorial que tantas consequências trouxe a nossa sociedade. Acreditamos que muitas dessas abordagens não são contraditórias $\mathrm{e}$, em alguns casos, inclusive se complementam. Desde que abandonados os "determinismos", que necessariamente levam à exclusão de outras possibilidades de explicação, o entendimento sobre esse período, necessariamente, tem que levar em conta diversos fatores. Crise e instabilidade política, atuação forte de governos e empresas transnacionais na defesa de seus interesses econômicos; necessidade de modificação do modelo de desenvolvimento econômico para o grande capital; interesses internos de se vincular ao capital internacional; papel estratégico dos agentes envolvidos, entre outros fatores. 
No entanto, o entendimento do que se passou nesse período não deve ficar restrito a um debate acadêmico. É necessário que entendamos esse processo, para que a história não se repita. Da mesma forma, é necessário o resgate desse período, para que a sociedade consiga avançar em pontos ainda não consolidados para a democracia, como a deformação da representação política; o aumento de poderes do Senado Federal; a centralização de poderes nos executivos; a lentidão no sistema jurídico e, inclusive, o questionamento das condições em que foi feita parte da dívida externa brasileira e suas consequências atuais. Esses problemas pertencem ao legado que o período militar deixou ao país. Como não é objetivo do presente trabalho, não nos preocuparemos em analisar de forma mais detida estas questões, apenas queremos de passagem lembrar que nosso país ainda não conseguiu se livrar de elementos autoritários que foram criados durante o período militar e que limitam nosso processo democrático. ${ }^{6}$

\section{THE CIVIL-MILITARY COUP OF 1964: SOME POSSIBILITIES ABOUT ITS HISTORICAL MEANING}

Abstract: This study aims to delineate a brief overview about the conditions in which the 1964 Brazilian Coup d'etat took place. It also aims to discuss some interpretations about the meaning of the Coup and the possible consequences if the actors involved had made different options in that historical moment.

Keywords: Coup d'etat. Military dictatorship. Historical conceptions.

\section{Notas}

${ }^{1}$ Sobre a política norte-americana para a América Latina no período e seu apoio ao golpe de 1964 no Brasil, ver FICO, Carlos. O grande irmão - da Operação Brother Sam aos anos de chumbo. Rio de Janeiro: Civilização Brasileira, 2008. O autor consultou extensa documentação do Arquivo Nacional dos Estados Unidos e busca discutir a política norte-americana, que, segundo ele, estava decidida a impedir que surgisse "outra Cuba" no continente. Neste sentido, o Brasil representava um ponto estratégico, o que levou o governo dos EUA a patrocinar uma série de ações na tentativa de garantir o controle político e econômico do país.

${ }^{2}$ Segundo Mendonça e Fontes, a política econômica adotada pelo regime favorecia a concentração de grandes capitais, potencializada pelo Estado. Como 


\section{Renato da Silva Della Vechia}

exemplo, as autoras citam a institucionalização dos preços oligopolistas, "pois os setores dominados pelo grande capital, tendo por base empresas com ampla utilização de tecnologia, mais eficientes, portanto, tornaram-se os padrões para a fixação dos preços." Tal política resultou "[...] no estrangulamento de pequenas e médias empresas, cuja estrutura de custos variava de unidade produtiva a outra, representando uma via direta de concentração de empresas e de capitais." SINGER, Paul. A crise do milagre. Rio de Janeiro: Paz e Terra, 1977. p. 86-87. Apud MENDONÇA, Sônia Regina; FONTES, Virgínia. Historia do Brasil recente (1964-1985). São Paulo: Editora Ática, 1988. p. 28-29.

${ }^{3}$ A Operação Bandeirantes (OBAN) foi criada em 1969, em São Paulo, com o objetivo de centralizar as operações de combate às organizações revolucionárias. A iniciativa partiu do comando do II Exército e da Secretaria de Segurança Pública do Estado de São Paulo, local onde as ações da guerrilha urbana mais se multiplicaram. A OBAN tinha caráter extralegal, uma vez que não constava de nenhum organograma do serviço público. Segundo Gorender, “[...] os problemas decorrentes desta circunstância se resolveram mediante transferência de recursos de outros órgãos já existentes e do apelo a contribuições de grandes empresas brasileiras e multinacionais." GORENDER, Jacob. Combate nas trevas. $5^{a}$ edição. São Paulo: Editora Ática, 1999. p. 156-157.

${ }^{4}$ Sobre os grupos beneficiados pelo golpe, especialmente os setores empresariais, ver DREIFUSS, René Armand. 1964: A conquista do estado. Ação política, poder e golpe de classe. Petrópolis: Editora Vozes, 1981. Tal discussão está contemplada de forma mais específica no capítulo IX: "O complexo IPES-IBAD no Estado - A ocupação dos postos estratégicos pela elite orgânica". p. 417-479.

${ }^{5}$ Assassinado em 28 de março de 1968, enquanto almoçava no Calabouço, durante um confronto dos estudantes com as forças repressivas.

${ }^{6}$ Para uma maior discussão sobre a transição inconclusa, ver SALLUM JR., Brasílio. Transição Política e Crise de Estado. In Revista Lua Nova, n. 32. CEDEC, 1994. Para ele, "No caso brasileiro, a transição política não se inicia nem conclui-se nos anos 80. Começa em 1973, quando a cúpula do regime militar que dominava o país desde o golpe de 1964 escolhe o Gen. Ernesto Geisel para ocupar a Presidência da República. E não se encerra nos anos 80, pois mesmo depois da eleição direta do presidente da República, em 1989, ele não governa sob uma ordem institucional expressiva de um pacto político estável”, p. 133.

\section{Referências}

ALVES, Mário. A burguesia nacional e a crise brasileira. In: Estudos Sociais, n. 15 dez. 1962. 
ARQUIDIOCESE DE SÃO PAULO. Brasil: Nunca Mais. Petrópolis: Editora Vozes, 1985.

BENEVIDES, Maria Victória de Mesquita. O Governo Kubitschek. Desenvolvimento Econômico e Estabilidade política. Rio de Janeiro: Paz e Terra, 1976.

BOURDIEU. Pierre; PASSERON, Jean-Claude. O Tempo e o Espaço no Mundo Estudantil. In: BRITTO, Sulamita de. Sociologia da Juventude, IV. Os Movimentos Juvenis. Textos Básicos de Ciências Sociais. Rio de Janeiro: Zahar Editores, 1968.

DREIFUSS, René Armand. 1964: A Conquista do Estado: Ação Política, Poder e Golpe de Classe. Petrópolis: Editora Vozes, 1981.

FICO, Carlos. O grande irmão - da Operação Brother Sam aos anos de chumbo. Rio de Janeiro: Civilização Brasileira, 2008.

FIGUEIREDO, Argelina Cheilub. Democracia ou Reformas? Alternativas democráticas à crise política: 1961-1964. Rio de Janeiro/São Paulo: Paz e Terra, 1993.

GORENDER, Jacob. Combate nas Trevas - A Esquerda Brasileira: das ilusões perdidas à Luta Armada. 2. ed. São Paulo: Editora Ática, 1998.

GORENDER, Jacob. Era o Golpe de 64 inevitável?. In: TOLEDO, Caio Navarro de (Org.). 1964: Visões Críticas do Golpe. Democracia e Reformismo no Populismo. Campinas, São Paulo. Editora da UNICAMP, 1997.

LINZ, Juan. Regimes Autoritários. In: PINHEIRO, Paulo Sérgio (Coord.). O Estado Autoritário e Movimentos Populares. Rio de Janeiro: Editora Paz e Terra, 1979.

OLIVEIRA, Francisco de. Dilemas e perspectivas da economia brasileira no pré64. In: TOLEDO, Caio Navarro (Org.). 1964 Visões Críticas do Golpe. Democracia e Reformismo no Populismo. Campinas: Editora da UNICAMP, 1997.

SALLUM JR., Brasílio. Transição Política e Crise de Estado. In: Revista Lua Nova, n. 32. CEDEC, 1994.

SERRA, José. As Desventuras do Economicismo: 'Três teses equivocadas sobre a conexão entre autoritarismo e desenvolvimento. In: COLLIER, David. O Novo Autoritarismo na América Latina. Rio de Janeiro. Editora Paz e Terra.

SINGER, Paul. A crise do milagre. Rio de Janeiro: Paz e Terra, 1977. p. 86-87. In: MENDONÇA, Sônia Regina; FONTES, Virgínia. Historia do Brasil recente (1964-1985). São Paulo: Editora Ática, 1988.

. O Significado do Conflito Distributivo no golpe de 64. In. TOLEDO, Caio Navarro de (Org.). 1964: Visões críticas do golpe. Democracia e Reformismo no populismo. Campinas: Editora da Unicamp, 1997. 


\section{Renato da Silva Della Vechia}

VENTURA, Zuenir. 1968: O ano que não terminou: A aventura de uma geração. Rio de Janeiro: Editora Nova Fronteira, 1998.

Recebido em: 30/05/2012

Aprovado em: 12/09/2012 